\title{
A Modeling Approach to Simulate the Behavior of Reinforced Concrete Shear Walls Using OpenSees
}

\author{
${ }^{1}$ Abdallah Montaser, ${ }^{2}$ Ezz Eldin Mostafa, ${ }^{3}$ Ahmed Ghallab \\ ${ }^{1}$ Teaching Assistant, Department of Structural Engineering, Faculty of Engineering, Ain Shams University, Cairo, Egypt \\ ${ }^{2}$ Assistant Professor, Department of Structural Engineering, Faculty of Engineering, Ain Shams University, Cairo, Egypt \\ ${ }^{3}$ Professor of Concrete Structures, Department of Structural Engineering, Faculty of Engineering, Ain Shams University, Cairo, \\ Egypt
}

\begin{abstract}
Recently, many analytical models have been proposed to simulate the behavior of Reinforced Concrete (R.C.) structural walls. The highly available experimental data and the rapid development of computers computational efficiency aided to develop more sophisticated and realistic modeling techniques. However, a simple model with little computational effort will be appreciated. A force-based fiber-section element is used in this study to simulate the behavior of R.C. structural walls exposed to quasi-static cyclic lateral loading. OpenSees is used to develop the analytical models while Response-2000 software is used to extract the wall sectional shear behavior to aggregate it back into the OpenSees fiber element. It was found that the modeling approach could simulate the experimentally measured wall behavior with an acceptable degree of accuracy. Finally, modeling capabilities are assessed, and recommendations for governing factors are given for modeling R.C. structural walls using force-based element in OpenSees.
\end{abstract}

Keywords: Structural Walls, Cyclic Loading, Fiber Section, Force-based Element.

\section{INTRODUCTION}

Using Reinforced Concrete (R.C.) shear walls in buildings located in high seismic areas is very common. They can provide adequate strength and stiffness for structures provided that proper design is considered. Hence, extensive experimental and analytical studies were conducted to investigate the nonlinear response of R.C. shear walls and to assess their demands accurately [1-4].Shear walls can be modeled either using micro-models (i.e. finite element) or macro-models. Although micro models can be used to provide accurate results and to describe the element local response, it is impractical to use it in simulating buildings with a large number of elements as they consider time and effort consuming. On the contrary, macro-modeling approach is more practical for modeling complex structures to capture the wall global response accurately with less computational time and effort [1].

\section{LITERATURE REVIEW}

Many macro-model techniques are used to simulate shear walls behavior. Clough et al., [5] introduced the twocomponent model which couldn't represent the degradation features. Giberson [6] developed the one vertical line element (OVLEM) at which plasticity is only limited at element ends which are called plastic hinge regions. The lumped plasticity model is very simple and can save time and computational effort extensively. It can simulate many features depending on the assumed hysteretic rule. The main disadvantage of lumped plasticity models is the assumption of plastic hinge locations and concentrating them at zero-length elements which doesn't depict the structure real behavior and doesn't allow tracing damage propagation along the wall. One another demerit in this technique is the prior hysteretic rule assumptions which requires much experience and follows empirical rules. Properties of both models are shown in Figure 1.

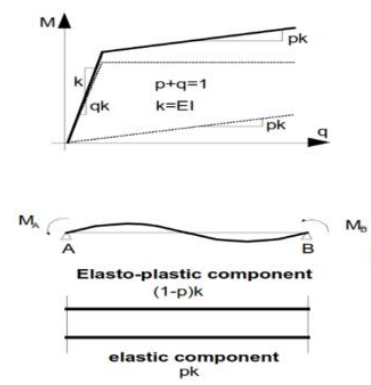

(a) (b)

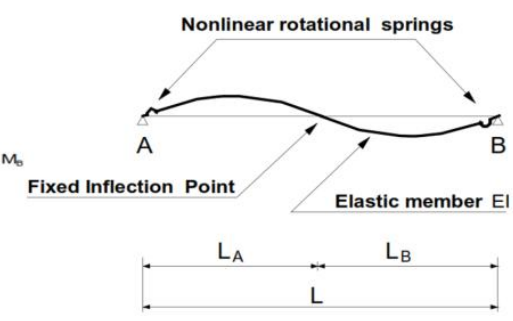

Figure 1: (a) Two-component model (b) OVLEM

Recently, fiber-based modeling has been proved to be a promising technique [1]. It could be considered a simplified form of the finite element micro-model and a complicated form of the macro-model. In this technique, the wall is represented by one element with distributed plasticity along its whole length. Several control sections divide the element. Each of them is discretized into certain number of fibers, as shown in Figure 2. Each fiber is then assigned a uniaxial hysteretic stress-strain relationship according to its type (i.e. concrete, steel...etc.). Wall global behavior is then extracted 
ISSN (online): 2581-3048

from integrating the behavior of all control sections. The advantage of fiber-based modeling over the lumped plasticity models is that the plasticity can form at any location inside the element which is closer to reality. Also, it can describe details of section geometry. Another advantage is that it needs implementing material constitutive relationship for each fiber which is more realistic and easier than the pre-assuming section moment-curvature relationships.

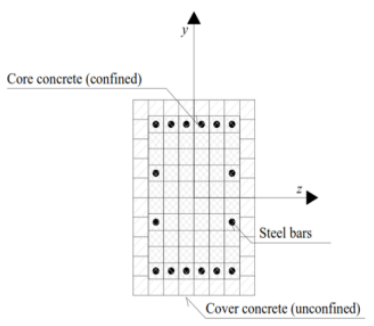

(b)

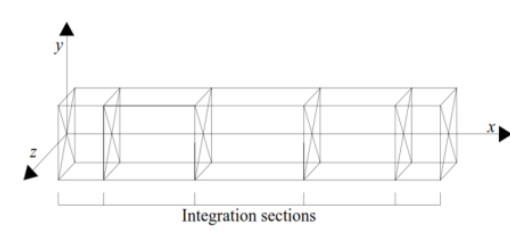

(a)
Figure 2: (a) fiber discretization in fiber-based modelling (b) Element controlling sections

Fiber-based element is classified according to its formulation into Displacement-Based Element (DBE) and Force-Based Element (FBE). In DBE, a displacement shape function is assumed, and element forces are found by applying virtual work principles. The basic shape function assumption is based on a constant axial strain and linear curvature distribution along the wall. This assumption could be valid for linear analysis but, it is not accurate for nonlinear analysis of shear walls. Hence, mesh refinement of the DBE is necessary to enhance the simulation procedure and capture the highly inelastic curvature distribution at plastic hinge locations. On the contrary, FBE assumes the force field instead of the displacement field, with constant axial force and linear moment distribution throughout the wall. This assumption is valid for nonlinear wall response provided that, no distributed loads act on the element. So, FBE is more accurate than DBE and uses a fewer number of elements to simulate the wall which reflects on the analysis computation effort. The only approximation exists in determining the number of controlling sections inside the element for numerical integration. Figure 3 shows the curvature distribution assumption of DBE and FBE [7].
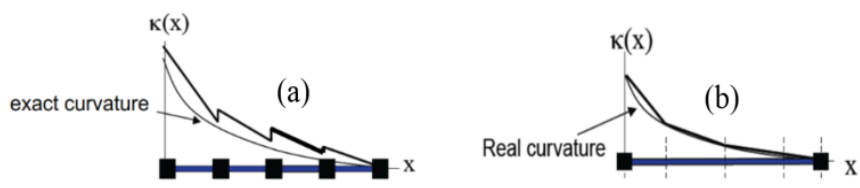

Figure 3: Curvature distribution according to (a) DBE (b) FBE

Results of two shear walls tested by Thomsen and Wallace [3] and Tran and Wallace [4] are used to verify the analytical model. Details of these shear walls and the proposed analytical models are as follows.RW2 was tested by Thomsen and Wallace [3] as a part of a research program aiming to assess the ability to use the displacement-based approach for R.C shear walls design. It is, approximately quarter-scale (four stories), structural wall, with aspect ratio equal 3. Tran and Wallace [4] have conducted a test on RW-A20-P10-S63 as a part of a research program aiming to investigate the effect of axial and average shear stress levels on the behavior of R.C. shear walls with different aspect ratios. It had an aspect ratio equals to 2. Walls cross-section details, test matrices, and measured material data are presented in Figure 4 and Table 1.

Table I: Details of wall specimens and measured material data

\begin{tabular}{|c|c|c|c|c|c|c|c|c|c|}
\hline \multirow{3}{*}{ Wall } & \multirow{3}{*}{$\begin{array}{l}\text { Wall Dimensions } \\
\text { (length*height" }{ }^{*} \text { thick.) } \\
(\mathrm{mm})\end{array}$} & \multirow{3}{*}{$\begin{array}{l}\text { Wall } \\
\text { aspect } \\
\text { ratio }\end{array}$} & \multicolumn{3}{|c|}{ Concrete properties } & \multirow{2}{*}{\multicolumn{2}{|c|}{$\begin{array}{l}\text { Reinforcing bars } \\
\text { Boundary }\end{array}$}} & \multirow{2}{*}{\multicolumn{2}{|c|}{ Web reinforcement }} \\
\hline & & & compressive & $\begin{array}{l}\text { Strain } \\
\text { at peak }\end{array}$ & $\frac{P_{\text {axial }}}{u^{\prime}}$ & & & & \\
\hline & & & $\begin{array}{l}\text { strength } \\
\text { (Mpa) }\end{array}$ & $\begin{array}{l}\text { stress* } \\
\left(10^{-3}\right)\end{array}$ & & Config. & $\begin{array}{l}F_{x} \\
(\underline{M} p a)\end{array}$ & Config. & $\begin{array}{l}F_{Y} \\
(M p a)\end{array}$ \\
\hline $\mathrm{RW}_{2}$ & $\left(1220^{*} 3660^{*} 102\right)$ & 3.0 & 42.8 & 2.100 & 0.072 & $8 \# 3$ & 434 & $\begin{array}{l}\text { 4\#2@191 } \\
\mathrm{mm}\end{array}$ & 448 \\
\hline $\begin{array}{l}\text { RW- } \\
\text { A20- } \\
\text { P10- } \\
\text { S63 }\end{array}$ & $\left(1220^{*} 2440^{*} 150\right)$ & 2.0 & 48.6 & 2.014 & 0.073 & $8 \# 6$ & 477 & $\begin{array}{l}5 \# 3 @ 152 \\
\mathrm{~mm}\end{array}$ & 443 \\
\hline
\end{tabular}

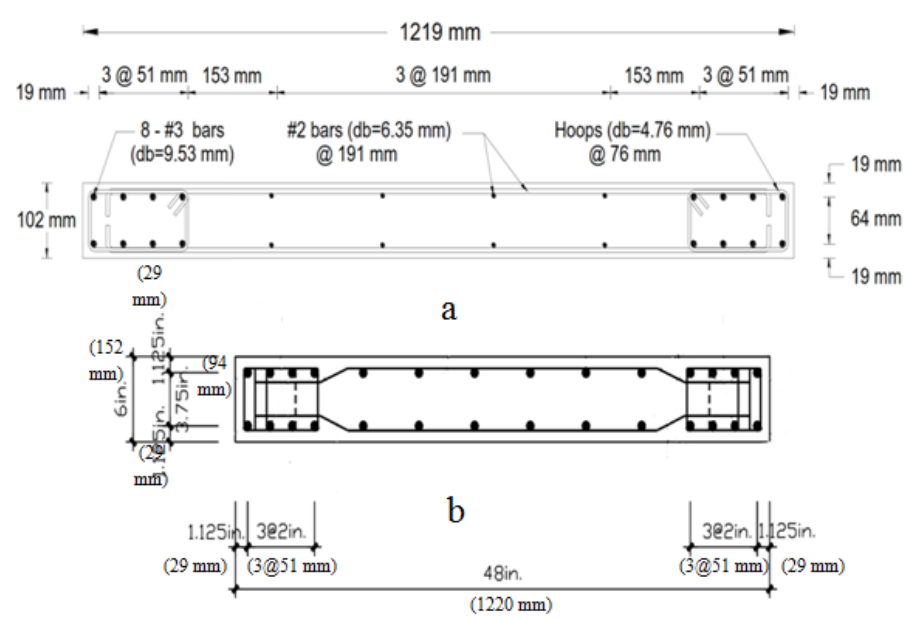

Figure 4: Cross-section details of (a) RW2 (b) Rw-A20-P10-S63

RW2 was first subjected to a constant axial load of approximately, $\left(0.072 \mathrm{Ag} * \mathrm{fc}^{\prime}\right)$ at its top-level then a displacement-controlled quasi-static cyclic loading was applied to the specimens up to a drift level of $2.5 \%$. For RWA20-P10-S63, a constant axial load of approximately, $(0.073$ $\left.\mathrm{Ag} * \mathrm{fc}^{\prime}\right)$ was applied at its top-level then a quasi-static cyclic loading was applied to the specimen. The first three cycles were load-controlled up to 0.75 of the expected yield point and then followed by displacement-controlled loading up to a drift level of $4 \%$.

\section{ANALYTICAL MODELS}

A fiber-based macro-model with distributed plasticity is adopted in the study. Due to the non-objective prediction of element curvature of the (DBE) discussed before, the (FBE) was chosen to simulate wall behavior. Analytical models are 
ISSN (online): 2581-3048

developed using OpenSees version 3.0.3 and Response-2000 version 1.0.5. OpenSees [8] was chosen in the study to simulate elements and buildings as it is open source and offers advanced capabilities for modeling and analyzing structures subjected to static and dynamic loads in linear and non-linear stages. Response-2000 is used in the study to define the sectional shear deformations and assign them back into the fiber section used in OpenSees. It was originally developed by Bentz and Collins [9] to calculate strength and ductility for R.C. cross-sections exposed to combined axial, flexural and shear loads relying on beam theory and the Modified Compression Field theory [10].

Each wall cross-section is discretized into finite number of fibers, each fiber is assigned a uniaxial material stress-strain relationship (e.g. unconfined, confined concrete and reinforcing bars). The fiber dimensions are taken as $(10 \mathrm{~mm} * 10 \mathrm{~mm})$, as it has showed a suitable balance between appropriate accuracy and computational effort. Figure 5 shows fiber section of RW2 used in the analysis.

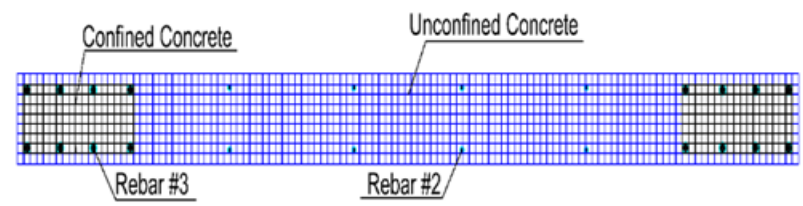

Figure 5: Fibre-section of the wall (RW2) as implemented in OpenSees

\section{a) Concrete Constitutive Model}

OpenSees provides a wide variety of material models to simulate concrete behavior [11-14]. Concrete07 which was developed by Waugh [15] as an implementation of the Chang and Mander concrete model[14] is chosen in the study to represent concrete characteristics. It approximates the unloading and reloading curves to a trilinear relation to enhance modeling computational efficiency and numerical stability. Figre 6 shows the Chang and Mander monotonic concrete envelope curve.

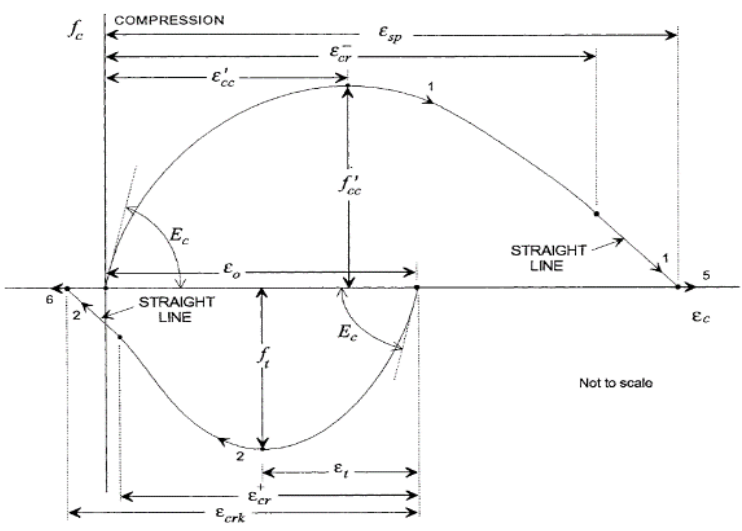

Figure 6: Compression and tension envelope curves byChang and Mander[14]
Concrete07 requires definition of some parameters which are; concrete compressive strength $\left(f_{c}{ }^{\prime}\right)$, corresponding compressive strain $\left(\varepsilon_{c}{ }^{\prime}\right)$, concrete initial elasticity modulus $\left(E_{c}\right)$, concrete tensile strength $\left(f_{t}\right)$, corresponding tensile strain $\left(\varepsilon_{t}\right)$, curve shape parameter $(r)$ and non-dimensional terms $\left(x_{c r}\right.$ and $x_{c r}{ }^{+}$) to define the point where the straight-line descent starts in compression and tension respectively. Following, a discussion of the calibrated input parameters for the tested walls used to verify the analytical model.

1. For unconfined concrete, empirical relations proposed by Chang and Mander [14] were used to calculate the initial values of the controlling parameters form the following equations:

$$
\begin{gathered}
E_{c}=8200\left(f_{c}^{\prime}\right)^{3 / 8} M P a \\
\varepsilon_{c}^{\prime}=\frac{\left(f_{c}^{\prime} M P a\right)^{0.25}}{1150} \\
r=\frac{\left(f_{c}^{\prime} M P a\right)}{5.2}-1.9
\end{gathered}
$$

The above parameters were calibrated and refined to match the cylinder test specimens' results of the tested walls. For RW2, the average compressive strength for cylinder specimen at the testing time was found to be $42.80 \mathrm{MPa}$, the average strain at peak compressive strength was found to be 0.0021 . The calibrated values of $\left(E_{c}\right)$ and shape parameter $(r)$ are $31000 \mathrm{MPa}$ and 6.35, respectively. The OpenSees material "MinMax" is used and given a strain limit value of 0.005 representing the calibrated unconfined concrete crushing strain.

For RW-A20-P10-S63, the average compressive strength for cylinder specimen was found to be $48.60 \mathrm{MPa}$, the average strain at peak compressive strength was found to be 0.002014 . The calibrated value of $\left(E_{c}\right)$ and shape parameter $(r)$ are 35180 $\mathrm{MPa}$ and 10.0, respectively. The unconfined concrete crushing strain is set as 0.0045 . The parameter $\left(x_{c r}{ }^{-}\right)$is recommended to be taken as 2 by Chang and Mander [14] and Waugh [15]. Figure 7 shows the calibration of the unconfined concrete compressive parameters of RW2 and RW-A20-P10-S63.

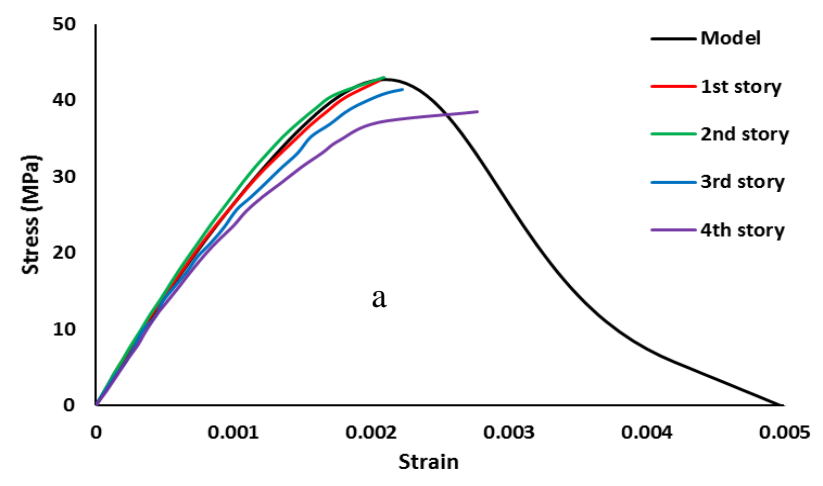


ISSN (online): 2581-3048

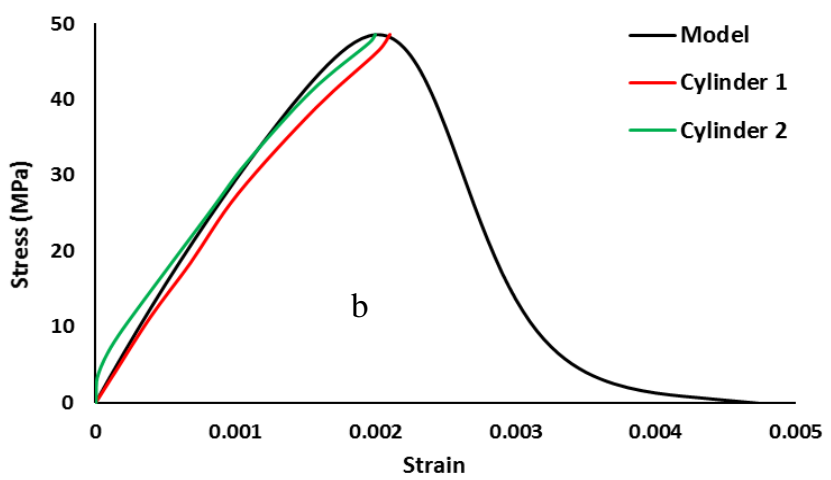

Figure 7: Calibration of the unconfined concrete constitutive model for (a) RW2 (b) RW-A20-P10-S63

2. The parameters of the confined concrete model were calculated using Mander et al., empirical relations [16]. The initial elasticity modulus of confined concrete is similar to the unconfined modulus while the confined concrete shape parameter $(r)$ has a lower value than the unconfined concrete shape parameter to achieve a less steep descending branch. Figure8 shows the calibrated confined and unconfined concrete compressive parameters for RW2 and RW-A20-P10-S63.

$$
r=\frac{n}{n-1}
$$

Where $n$ is a parameter controlling the curve ascending branch and can be calculated from the following equation:

$$
n=\frac{E_{c} \varepsilon_{c c}^{\prime}}{f_{c c}^{\prime}}
$$

Where $f_{c c}{ }^{\prime}$ and $\varepsilon_{c c}{ }^{\prime}$ are the confined concrete compressive strength and corresponding strain, respectively.
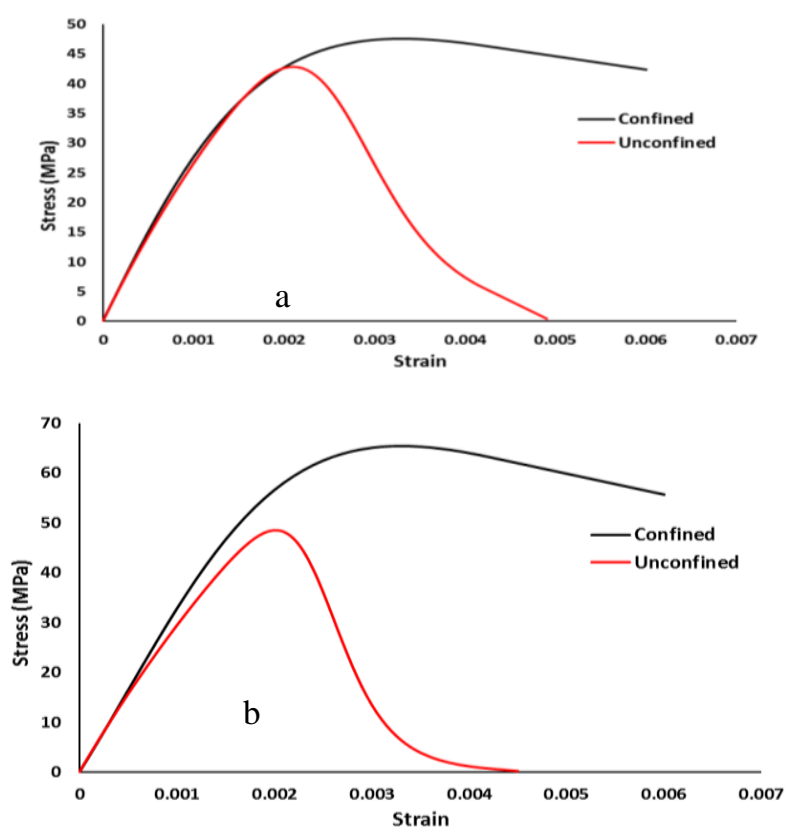

Figure 8: Unconfined and confined concrete calibrated model in compression for the tested walls (a) RW2 (b) RW-A20-P10-S63
https://doi.org/10.47001/IRJIET/2021.505010

3. The tension envelope stress-strain relationship proposed by Concrete07 is based on Chang and Mander concrete model [14]. Values of tension envelope curve were calibrated to comply with Belarbi and Hsu [17] tension concrete model as it had been validated experimentally by several studies [18-20]. The parameter $\left(x_{c r}{ }^{+}\right)$is set as large value (i.e. 100) to consider tension stiffening effects in concrete. Table 2 summarizes the calibrated values of compression and tension parameters controlling the hysteric model of concrete.

Table II: Calibrated parameters of unconfined and confined constitutive

\begin{tabular}{|c|c|c|c|c|c|c|c|c|c|c|c|c|}
\hline \multirow{2}{*}{ Wall } & \multirow{2}{*}{$\begin{array}{l}E_{c} \\
\mathrm{MPa}\end{array}$} & \multicolumn{4}{|c|}{ Unconfined parameters } & \multicolumn{5}{|c|}{ Confined parameters } & \multicolumn{2}{|c|}{$\begin{array}{l}\text { Tension } \\
\text { parameters }\end{array}$} \\
\hline & & $\begin{array}{l}f c^{\prime} \\
\mathrm{MPa}\end{array}$ & $\varepsilon_{C}$ & $x \mathrm{cr}$ & Ecrush. & $\begin{array}{l}\text { fcc } \\
\mathrm{MPa}\end{array}$ & $\varepsilon c c$ & $r$ & $x c r$ & Ecrushing & $\begin{array}{l}\mathrm{fcr} \\
\mathrm{MPa}\end{array}$ & $\varepsilon t$ \\
\hline RW2 & 31000 & 42.8 & 0.0021 & 6.4 & 0.005 & 47.6 & 0.033 & 1.87 & 2 & 0.011 & 2.028 & 0 \\
\hline RW-A20-P10-S63 & 35180 & 48.6 & 0.002014 & $10^{2}$ & 0.0045 & 65.4 & 0.055 & 1.88 & 2 & 0.0175 & 2.161 & 0.00000 \\
\hline
\end{tabular}
concrete models of tested walls

\section{b) Reinforcement Model}

SteelMPF material available in OpenSees is preferred in this study compared to other models as it is computationally efficient and could simulate different reinforcing bars properties accurately. It was originally developed by Kolozvari et al. [2] as implantation of the Menegotto steel model [21] which was enhanced by Filippou [22] to comprise isotropic strain hardening. Figure 9 shows the Menegotto steel reinforcement model. SteelMPF requires a definition of twelve reinforcing steel material parameters which are yield strength in tension $\left(f_{y p}\right)$ and compression $\left(f_{y n}\right)$, initial Young's modulus $\left(E_{o}\right)$, tensile and compressive strain hardening ratios $\left(b_{p}\right)$ and $\left(b_{n}\right)$ respectively, the initial curvature parameter $\left(R_{o}\right)$, curvature deterioration parameters $\left(\alpha_{1}\right)$ and $\left(\alpha_{2}\right)$ and compressive and tensile isotropic hardening parameters $\left(a_{1}\right)$, $\left(a_{2}\right),\left(a_{3}\right)$ and $\left(a_{4}\right)$.

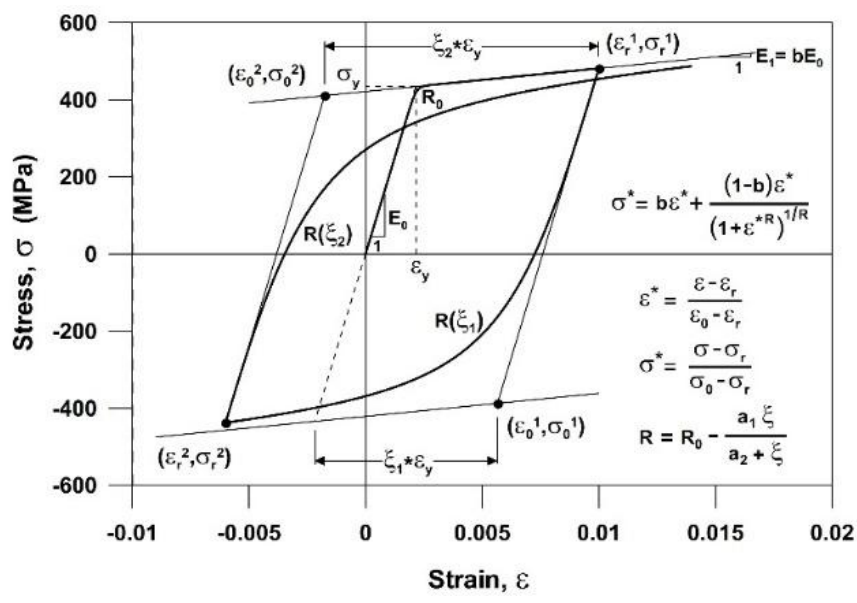

Figure 9: Constitutive Model for Steel by Menegotto[21]

The analytical yield strength and strain hardening ratios in compression and tension for different reinforcing bars were calibrated using the experimentally measured values of the monotonic tensile load tests[3-4] . The initial Young's 
ISSN (online): 2581-3048

modulus is set as $2 * 10^{5} \mathrm{MPa}$ for all bars. For mild reinforcing bars, tension yield strength and strain hardening ratio are calibrated to include tension stiffening effect as proposed by Belarbi and Hsu [17]. Calibration of $R_{o}, \alpha_{1}$, and $\alpha_{2}$, requires conducting a cyclic test on the reinforcing bars which is unavailable, hence, recommended values suggested by Elmorsiet al. [23] were initially considered $\left(R_{o}=20, \alpha_{1}=18.5\right.$, and $\left.\alpha_{2}=0.0015\right)$ and compared with those recommended byOpenSees manual ( $R_{o}$ between 10 and 20, $\alpha_{1}=0.925$ and $\alpha_{2}$ $=0.15)$. Finally, values of these parameters were set as $(20$, 18.5, and 0.15) as they have shown better simulation for wall behavior. Also, and as Isotropic hardening parameters calibration needs a cyclic test which is not available. They were taken as recommended by OpenSees manual.

SteelMPF formulation doesn't account for bar buckling in compression. To model bar buckling, Bedeir et al., [24] recommended modeling each steel bar with two fibers. The first one has an area equal to (15-30\%) area of the reinforcing bar and assigned a buckling strain using "MinMax" material where it loses its resistance after that limit. The other one has the rest of the bar area with only a tensile fracture strain. Tables 3 and 4 show the calibrated parameters used in the SteelMPF model.

Table III: Calibrated steel reinforcing bar parameters

\begin{tabular}{lll|ll}
\hline Parameter & RW2 & & \multicolumn{2}{c}{ Rw-A20-P10-S63 } \\
& $\# 2$ & $\# 3$ & $\# 3$ & $\# 6$ \\
$f_{v p}$ & 448 & 434 & 443 & 477 \\
$f_{v a}$ & 448 & 386 & 443 & 477 \\
$b_{b}$ & 0.02 & 0.02 & 0.02 & 0.01 \\
$b_{n}$ & 0.02 & 0.022 & 0.02 & 0.01 \\
$\varepsilon_{\text {buck }}$ & 0.005 & 0.011 & 0.0045 & 0.0175 \\
$\varepsilon_{f}$ & 0.1 & 0.12 & 0.068 & 0.082 \\
\hline
\end{tabular}

Table IV: Calibrated initial modulus, curvature degradation and isotropic hardening parameters for all reinforcing bars

\begin{tabular}{lllllllll}
\hline Parameter & $\mathrm{E}_{0}$ & $\mathrm{R}_{0}$ & $\alpha_{1}$ & $\alpha_{2}$ & $\mathrm{a}_{1}$ & $\mathrm{a}_{2}$ & $\mathrm{a}_{3}$ & $\mathrm{a}_{4}$ \\
Value & $\mathrm{MPa}$ & & & & & & & \\
\hline
\end{tabular}

\section{c) Shear Deformation}

The fiber-based element implemented in OpenSees considers only axial and flexural deformations and neglects shear deformations contribution. Hence, sectional shear deformations were calculated, assigned uniaxial material, and then aggregated into the OpenSees fiber element using section Aggregator command available in OpenSees.

Hence, the first step to get the shear deformations was to locate the section at which plastic shear deformations initiate which represents the wall center of rotation. So, Response2000 software was used to model each cantilever wall, apply the same experimental loads, and draw shear strain distribution along its length for each loading step till initiation of plastic shear deformation. Fig. (10-a) shows the application of this step to RW2. It can be noted that a lateral load of 103.4 $\mathrm{KN}$ has caused initiation of plastic shear deformations in a section located at distance $1.34 \mathrm{~m}$ from the wall base. After determining the section at which plastic shear deformations were first encountered, it was subjected to Incremental shear force and bending moment depending on its location to determine the shear -shear strain relation which was then idealized to a bilinear relation. Fig. (10-b) shows the application of this step to RW2. The idealized shear-shear strain relation was applied to all sections using the section aggregator command in OpenSees. Fig. (11) shows the same procedure to develop the bilinear shear relation of RW-A20P10-S63.
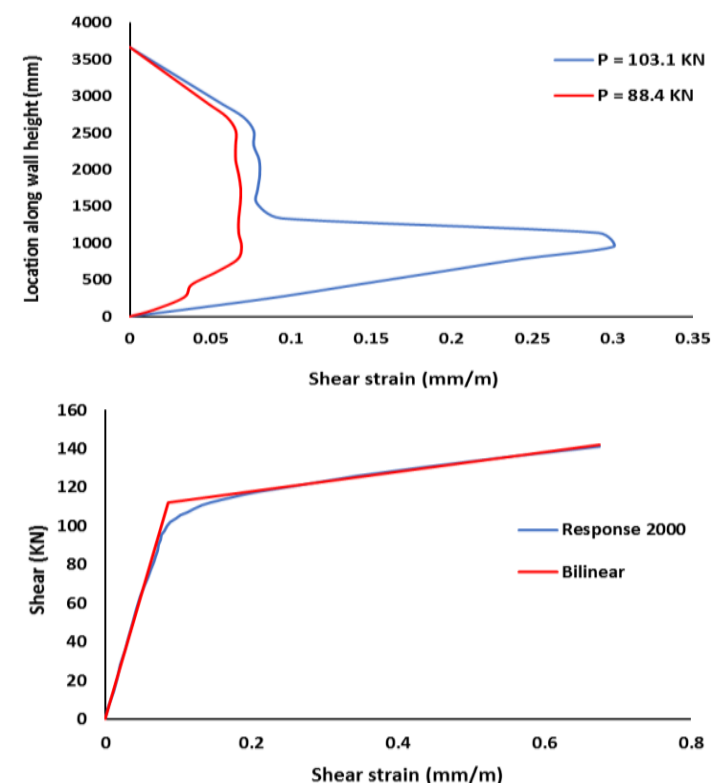

Figure 10: (a) Shear Strain Distribution (b) Bilinear Idealization of Shear Behavior of RW2
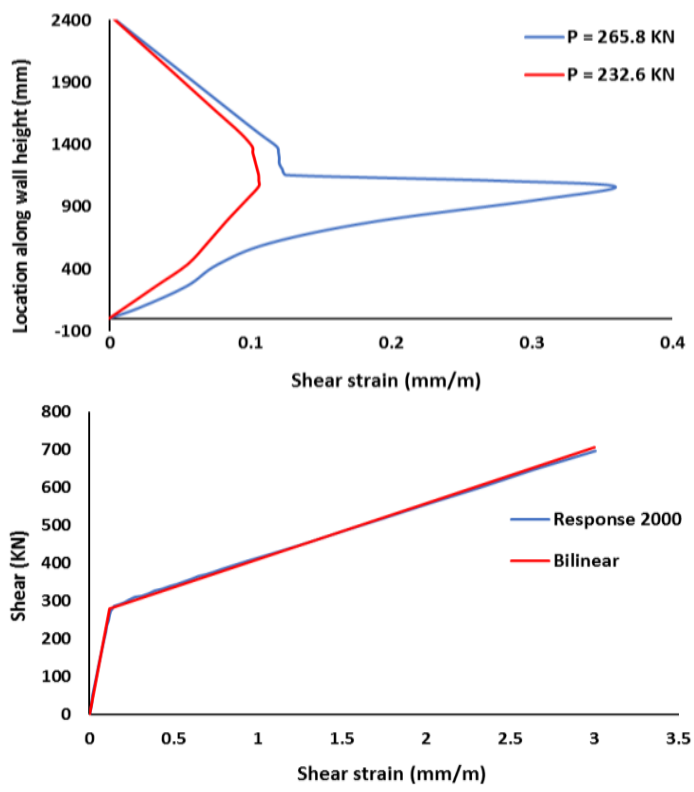

Figure 11: (a) Shear Strain Distribution (b) Bilinear Idealization of Shear Behavior of RW-A20-P10-S63 
It is noted that the section at which plastic shear deformations initiate at the studied shear walls is located approximately at distance equals $40 \%$ of wall height from its base which matches with previous studies' recommendations of the location of the horizontal shear spring in modeling shear walls with multi-vertical line element (MVLEM) [25]

\section{d) Localization of Plasticity}

In force-based models, the element is discretized into several integration points where, their numbers, locations, and weights are determined by the numerical quadrature rules. Each integration point represents a portion of element length $\left(L_{i}\right)$ equals to integration point weight $\left(W_{i}\right)$ multiplied by total element length $(L)$. Sectional forces are calculated at those integration points and then integrated over the whole length to maintain the global response. Due to concrete softening response, plasticity tends to concentrate at the section that reaches plasticity first (base integration section in our case). Hence, as the number of integration points increases, plasticity concentrates at limited element length leading to non-objective element response presented in rapid strength and stiffness degradation which is referred to as localization of plasticity.

There are two approaches to solve this modeling issue in elements with distributed plasticity. The first approach was introduced by Coleman and Spacone [26] at which, concrete post-peak stress-strain relationship is modified according to the location of integration points to maintain constant postpeak energy which is denoted by energy regularization. Coleman and Spacone modified the value of $\varepsilon_{20}$ (concrete strain corresponding to $80 \%$ strength degradation) in Kent and Park concrete model which is shown in Figure 12 according to the weight of integration points $\left(l_{p}\right)$ as the following:

$$
\varepsilon_{20}=\frac{G_{f}^{c}}{0.6 f_{c}^{\prime} l_{p}}-\frac{0.8 f_{c}^{\prime}}{E_{c}}+\varepsilon_{c}(6)
$$

Where $G_{f}^{c}$ is concrete compressive fracture energy.

Scott and Fenves [27] introduced another approach by changing the first integration section weight based on the plastic hinge length to maintain same concrete compressive fracture energy. Eq. 6 can be used to determine the plastic hinge length, Instead, it could be calculated by any empirical relationship (e.g. Bohl and Adebar equation) [28] which is given as the following:

$$
l_{p}=\left(0.2 l_{w}+0.05 l_{v}\right)\left(1-1.5 \frac{P}{A_{g} f_{c}^{\prime}}\right)(7)
$$

Where $l_{w}$ is wall length and $l_{v}$ is wall height.

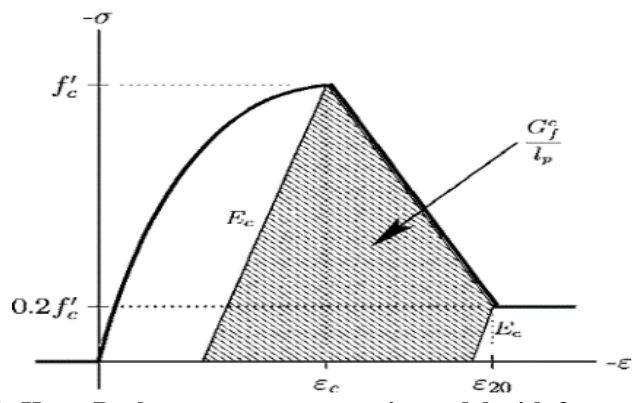

Figure 12: Kent-Park concrete stress-strain model with fracture energy in compression as a shaded area

In the second approach which was adopted in this study, shear walls were modeled as one FBE with two parts, the bottom part length is equal to twice $L_{p}$ having 2 GaussLobatto integration points, while the top part has 5 GaussLobatto integration points, as shown in Figure 13 where the plastic hinge length $\left(L_{p}\right)$ was calculated using Eq. 7. Table 5 summarize the plastic hinge length calculations for each wall. Figure 14 represents a comparison of RW2 lateral loaddisplacement curve when using the initial 5 Gauss-Lobatto integration points all over the wall entire length and after applying model regularization.
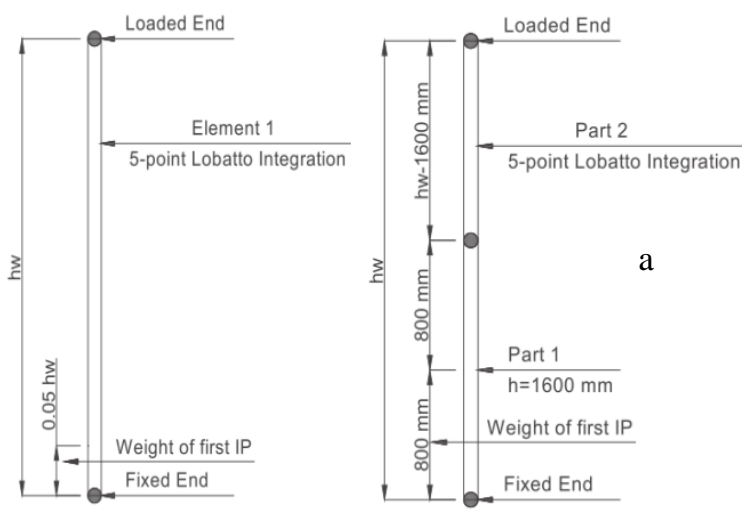

Figure 13: Schematic diagram of (a) initial model (b) regularized

\begin{tabular}{|c|c|c|c|c|}
\hline Wall & $\begin{array}{l}\begin{array}{l}L_{x} \\
\mathrm{~mm}\end{array} \\
\end{array}$ & $\begin{array}{l}L_{x} \\
\mathrm{~mm}\end{array}$ & $\frac{P}{A_{g} f_{c}^{\prime}}$ & $\begin{array}{l}l_{D} \\
\mathrm{~mm}\end{array}$ \\
\hline RW2 & 1220 & 3660 & 0.07 & 400 \\
\hline RW-A20-P10-S63 & 1220 & 2440 & 0.10 & 325 \\
\hline
\end{tabular}
wall model for RW2

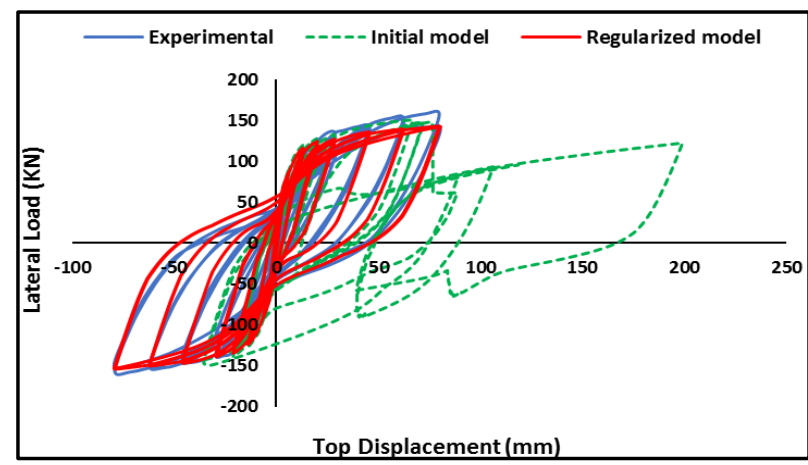

Figure 14: Effect of model regularization on RW2 loaddisplacement response 
ISSN (online): 2581-3048

\section{ANALYTICAL RESULTS}

Figures from 15 to 18 show the analytical and experimental lateral load-displacement relations of the studied walls (RW2 and RW-A20-P10-S63). The proposed Fiberbased models have shown an acceptable agreement with the experimental results based on the load capacity of each wall under cyclic loading in addition to representing different degradation features.

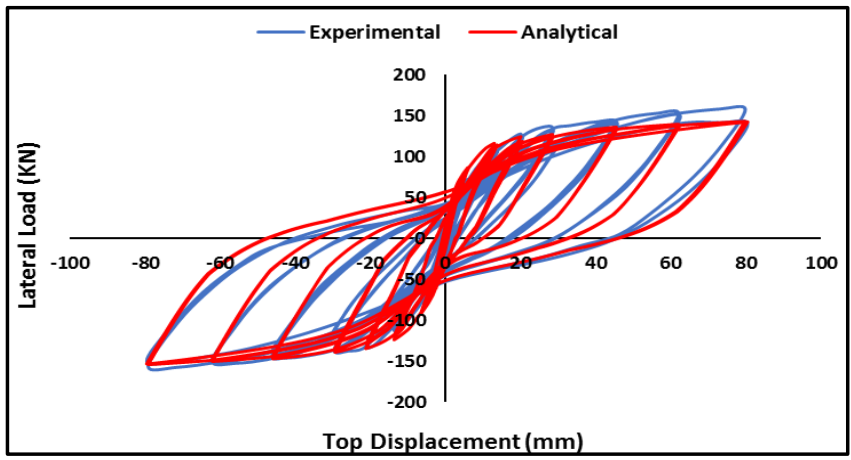

Figure 15: Analytical and Experimental Lateral Load-Top displacement relation for $R W 2$
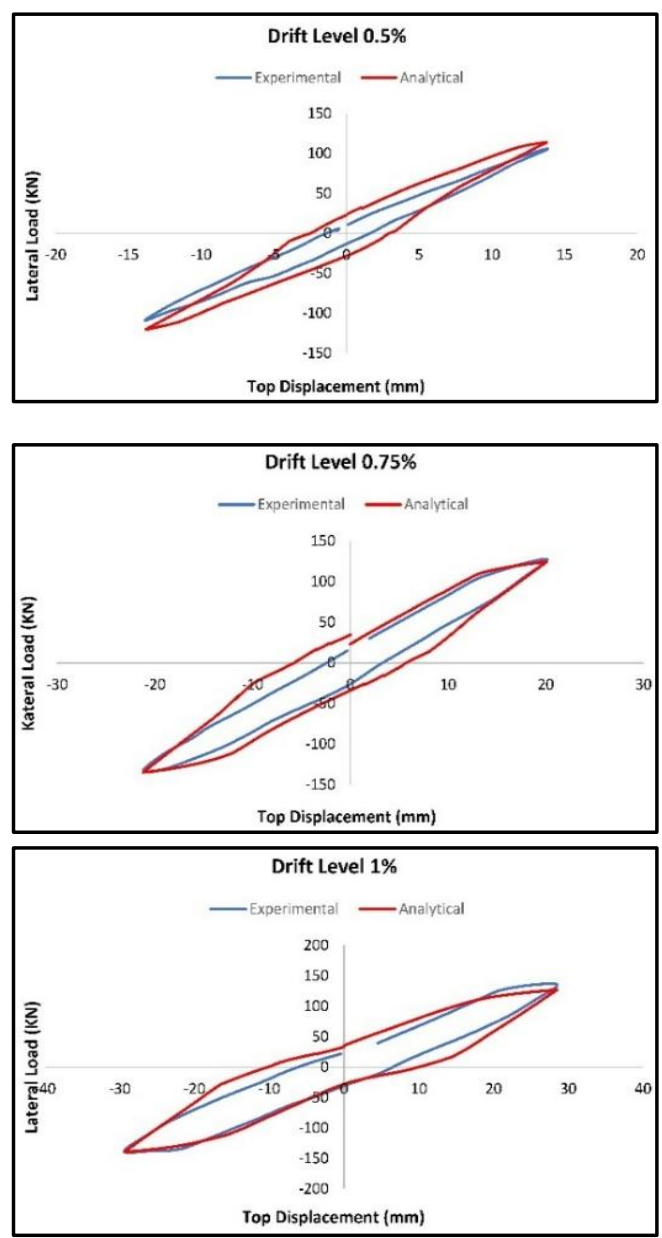

Volume 5, Issue 5, pp 59-67, May-2021 https://doi.org/10.47001/IRJIET/2021.505010

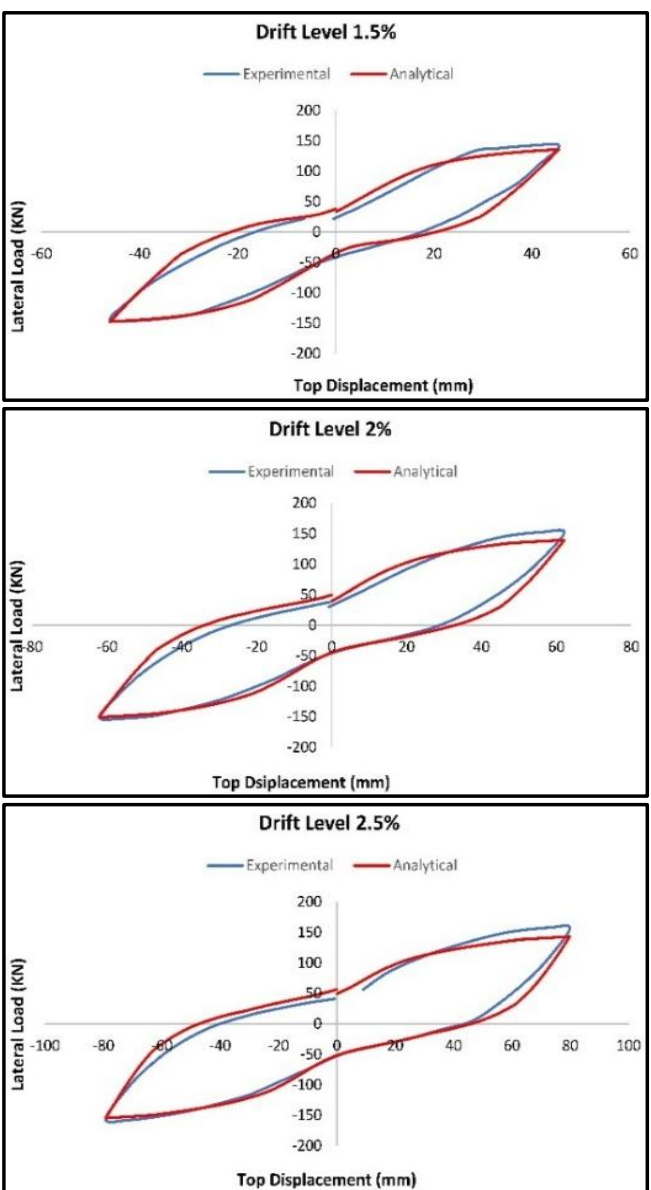

Figure 16: Analytical and Experimental Lateral Load-Top displacement relation for $R W 2$ at different lateral drift

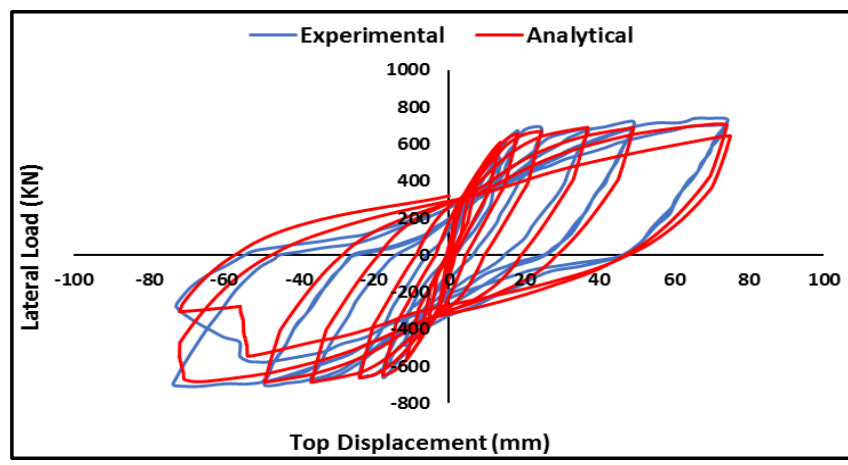

Figure 17: Analytical and Experimental Lateral Load-Top displacement relation for $\mathrm{RW}$-A20-P10-S63

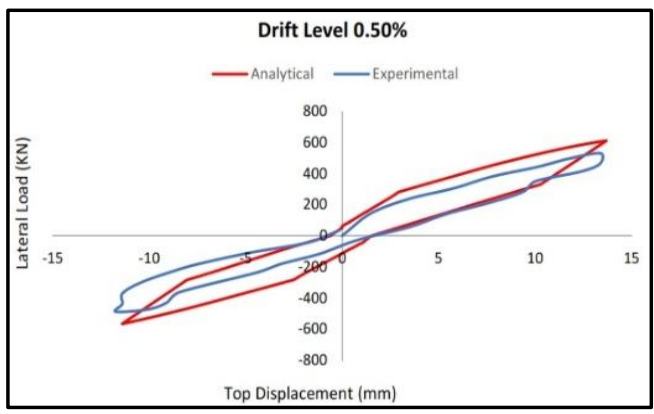


ISSN (online): 2581-3048
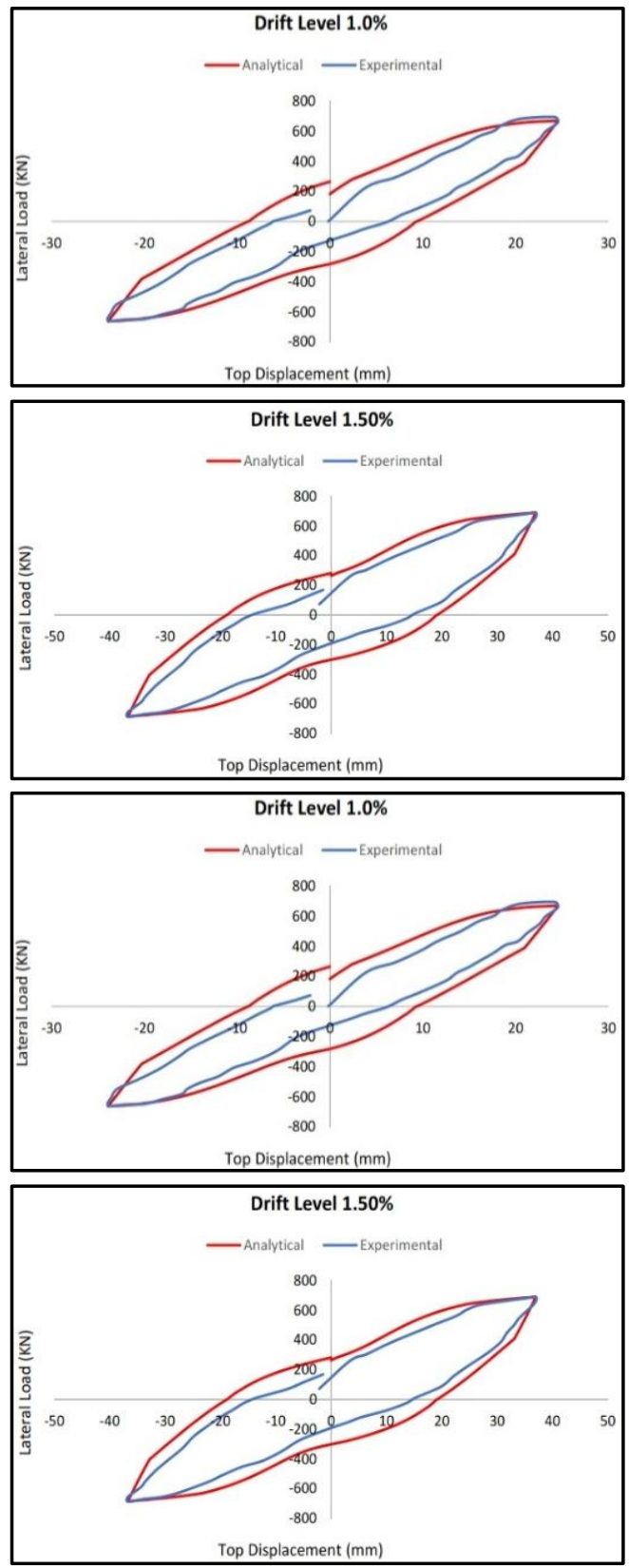

Figure 18: Analytical and Experimental Lateral Load-Top displacement relation for RW-A20-P10-S63 at different lateral drift ratios

\section{SUMMARY AND CONCLUSIONS}

This study introduces a simple realistic approach to simulate the response of R.C. structural walls with different aspect ratios under quasi-static lateral loading using OpenSees software. Based on analytical and experimentally measured results of the studied shear walls, it is found that:

- The modeling approach has proven to be accurate. The maximum error obtained from the model for the lateral load at each cycle didn't excess $10.6 \%$ and 14.1 for RW2 and RW-A20-P10-S63 respectively.

- A recommendation for values controlling the concrete and reinforcing bars cyclic behavior was given.
https://doi.org/10.47001/IRJIET/2021.505010

- The suggested solution of rapid softening response caused by the localization of plasticity is acceptable.

Some limitations need to be enhanced in future modeling such as providing flexibility to change the post-peak branch of concrete in the tension side. Also, the verification procedure is valid for slender wall with aspect ratio more than 2. Further studies regarding the behavior of R.C. shear walls can be done using the developed calibrated model.

\section{REFERENCES}

[1] Jalali A, Dashti F. Nonlinear behavior of reinforced concrete shear walls using macroscopic and microscopic models. Eng Struct 2010;32:2959-68. https://doi.org/10.1016/j.engstruct.2010.05.015.

[2] Kolozvari K, Orakcal K, Wallace JW. Shear-flexure interaction modeling for reinforced concrete structural walls and columns under reversed cyclic loading. Pacific Earthq Eng Res Center, PEER Rep 2015.

[3] Thomsen JH, Wallace JW. Displacement based design of reinforced concrete structural walls: an experimental investigation of walls with rectangular and t-shaped cross-sections: a dissertation 1995.

[4] Tran TA, Wallace JW. Cyclic testing of moderateaspect-ratio reinforced concrete structural walls. ACI Struct J 2015;112:653-66. https://doi.org/10.14359/51687907.

[5] Clough RW, Benuska KL, Wilson EL. Inelastic earthquake response of tall buildings. Proceedings, Third World Conf. Earthq. Eng. New Zeal., vol. 11, 1965.

[6] Giberson_1967.pdf n.d.

[7] Terzic V. G S Getting Started with OpenSees 2011.

[8] Mazzoni S, McKenna F, Scott MH, Fenves GL. OpenSees command language manual. Pacific Earthq Eng Res Cent 2006;264.

[9] Bentz EC, Collins MP. Response 2000. Softw Progr Load-Deformation Response Reinf Concr Sect 2000.

[10] Vecchio FJ, Collins MP. The modified compressionfield theory for reinforced concrete elements subjected to shear. ACI J 1986;83:219-31.

[11] Kent DC, Park R. Flexural members with confined concrete. J Struct Div 1971.

[12] Popovics S. A numerical approach to the complete stress-strain curve of concrete. Cem Concr Res 1973;3:583-99.

[13] Thorenfeldt E. Mechanical properties of highstrength concrete and applications in design. Symp. Proceedings, Util. High-Strength Concr. Norway, 1987, 1987. 
ISSN (online): 2581-3048

Volume 5, Issue 5, pp 59-67, May-2021

https://doi.org/10.47001/IRJIET/2021.505010

[14] Chang GA, Mander JB. Seismic energy based fatigue damage analysis of bridge columns: part 1 evaluation of seismic capacity. Natl Cent Earthq Eng Res 1994:230. https://doi.org/Technical Report NCEER-94-0006.

[15] Waugh JD. Nonlinear analysis of T-shaped concrete walls subjected to multi-directional displacements 2009.

[16] Mander JB, Priestley MJN, Park R. Conducted Providing the Stress-Strain Model for Confined Concrete. J Struct Eng 1989;114:1804-26. https://doi.org/10.1061/(ASCE)07339445(1988)114:8(1804).

[17] Belarbi A, Hsu TTC. Constitutive Laws of Reinforced Membrane Elements. ACI Struct J 1995;92:562-73.

[18] Pang X-BD, Hsu TTC. Behavior of reinforced concrete membrane elements in shear. Struct $\mathrm{J}$ 1995;92:665-79.

[19] Hsu TTC, Zhang L-X. Tension stiffening in reinforced concrete membrane elements. Struct J 1996;93:108-15.

[20] Hsu TTC, Zhu RRH. Softened membrane model for reinforced concrete elements in shear. Struct $\mathrm{J}$ 2002;99:460-9.

[21] Menegotto M. Method of analysis for cyclically loaded RC plane frames including changes in geometry and non-elastic behavior of elements under combined normal force and bending. Proc. IABSE Symp. Resist. Ultim. Deform. Struct. acted by well Defin. repeated loads, 1973, p. 15-22.

[22] Filippou FC, Bertero VV, Popov EP. Effects of bond deterioration on hysteretic behavior of reinforced concrete joints 1983 .

[23] Elmorsi M, Kianoush MR, Tso WK. Nonlinear analysis of cyclically loaded reinforced concrete structures. Struct J 1998;95:725-39.
[24] Bedeir H, Shedid M, Okail H, Hamdy O. Numerical modeling of a two story third-scale reinforced masonry shear wall building subjected to quasi-static lateral loading. Eng Struct 2019;181:310-23.

[25] Orakcal K, Wallace JW, Conte JP. Flexural modeling of reinforced concrete walls-model attributes. Struct $\mathbf{J}$ 2004;101:688-98.

[26] Coleman J, Spacone E. Localization issues in forcebased frame elements. J Struct Eng 2001;127:125765.

[27] Scott MH, Fenves GL. Plastic hinge integration methods for force-based beam-column elements. J Struct Eng 2006;132:244-52.

[28] Bohl A, Adebar P. Plastic hinge lengths in high-rise concrete shear walls. ACI Struct J 2011;108.

\section{AUTHOR'S BIOGRAPHIES}

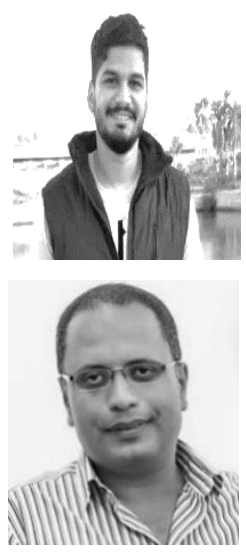

Abdallah Montaser, is a Teaching Assistant at Department of Structural Engineering, Faculty of Engineering, Ain Shams University, Cairo, Egypt.

Ezz El-Deen Mostafa, is an Assistant Professor at Department of Structural Engineering, Faculty of Engineering, Ain Shams University, Cairo, Egypt.

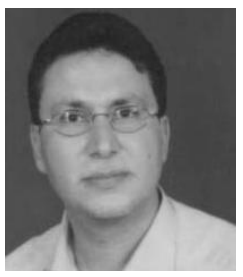

Ahmed Ghallab, is a Professor of Concrete Structures at Department of Structural Engineering, Faculty of Engineering, Ain Shams University, Cairo, Egypt.

\section{Citation of this Article:}

Abdallah Montaser, Ezz Eldin Mostafa, Ahmed Ghallab, "A Modeling Approach to Simulate the Behavior of Reinforced Concrete Shear Walls Using OpenSees" Published in International Research Journal of Innovations in Engineering and Technology - IRJIET, Volume 5, Issue 5, pp 59-67, May 2021. Article DOI https://doi.org/10.47001/IRJIET/2021.505010 